\title{
Crescentic glomerulonephritis complicating fibrillary glomerulonephritis: Response to Euro Lupus protocol treatment
}

\author{
Ananda Gurram ${ }^{1}$, Nirav Jasani ${ }^{1}$, Reginald Obi ${ }^{1}$, Karlene Hewan-Lowe ${ }^{2}$ \\ 1. Department of Nephrology and Hypertension, East Carolina University, Greenville, NC, USA. 2. Department of \\ Pathology, East Carolina University, Greenville, NC, USA.
}

Correspondence: Ananda Gurram. Address: Department of Nephrology and Hypertension, East Carolina University, Greenville, NC, USA. Email: gurrama@ecu.edu

Received: July 1, 2014

DOI : $10.5430 /$ crim.v1n2p230
Accepted: August 5, $2014 \quad$ Online Published: August 13, 2014

URL: http://dx.doi.org/10.5430/crim.v1n2p230

\section{Abstract}

Fibrillary glomerulonephritis (FGN) is a rare cause of glomerulonephritis with poor prognosis. No standard treatment exists. We report a case of crescentic FGN presenting as rapidly progressing renal failure needing hemodialysis and treated based on Euro lupus nephritis trial protocol of low dose cyclophosphamide and glucocorticoid for induction followed by azathioprine maintenance. Patient responded very well to this therapy and was able to get off hemodialysis and continues with stable stage 3 CKD after 1 year follow up.

\section{Keywords}

Fibrillary glomerulonephritis, FGN, Glomerulonephritis, GN, RPGN, Rapidly progressing glomerulonephritis, Chronic kidney disease (CKD)

\section{I ntroduction}

Fibrillary glomerulonephritis (FGN) comprises about $0.4 \%-1.0 \%$ of kidney biopsies and is characterized by the deposition of irregularly oriented, elongated, non-branching micro fibrils 10- to 30-nm thick in the mesangium and along the capillary walls. It typically presents with sub-nephrotic or nephrotic range proteinuria and often is associated with, crescentic disease, hypertension, and decreased glomerular filtration rate (GFR). The prognosis of FGN is poor, with up to $50 \%$ of patients progressing to end-stage renal disease (ESRD) within 2 years of diagnosis ${ }^{[1-6]}$.

FGN is usually idiopathic but is also associated with autoimmune diseases like SLE, Sjogren's syndrome, Grave's disease, hepatitis C, dysproteinemia's like multiple myeloma, malignancies including thyroid carcinoma, hepatocellular carcinoma, breast carcinoma, uterine carcinoma, prostate carcinoma, colon carcinoma, and renal cell carcinoma ${ }^{[7,8]}$. Pathophysiology of this disease is unknown since animal models of this disease is lacking. However it is thought that immune mediated process result in renal deposition of IgG (predominantly IgG-4) containing immune complexes ultimately resulting in formation of these fibrils ${ }^{[9,10]}$. 
Several retrospective case series and case reports describe treatment of FGN using blockade of the renin-angiotensinaldosterone axis and a variety of non-specific immunosuppressive therapies used in other glomerular diseases, such as steroids, cyclophosphamide, cyclosporine, mycophenolate mofetil and rituximab ${ }^{[1,11-12]}$. However, no treatment has been shown to improve long-term renal outcomes.

The efficacy of Low dose Cyclophosphamide in treatment of proliferative GN due to SLE was highlighted in the Euro lupus Nephritis trial protocol using IV cyclophosphamide at a cumulative dose of $3 g^{[13]}$. We present an interesting case of crescentic FGN patient treated with this protocol.

\section{Case presentation}

A 61-year-old African American woman with history of hypertension, COPD, Diabetes Mellitus type 2, CKD 3 and baseline creatinine of $1.25 \mathrm{mg} / \mathrm{dl}$ and estimated glomerular filtration rate (eGFR) of $53 \mathrm{ml} / \mathrm{min}$, presented to our hospital intensive care unit from an outside hospital where she was admitted with generalized weakness and acute renal failure with creatinine of $3.15 \mathrm{mg} / \mathrm{dl}$. Her condition at the outside hospital worsened with respiratory failure and renal failure (creatinine up to $6.25 \mathrm{mg} / \mathrm{dl}$ ) requiring mechanical ventilation and need for hemodialysis. Her work up revealed nephrotic range proteinuria of $5.8 \mathrm{gm} / 24 \mathrm{hr}$. Serologic workup was negative and renal ultrasound showed normal size kidneys and echogenicity (see Table 1). Due to worsening renal failure, hemodialysis was initiated and a renal biopsy was subsequently performed. This showed a diffuse crescentic proliferative glomerulonephritis (see Figure 1) with endocapillary, hyper cellularity involving about $75 \%$ of sampled glomeruli. Electron microscopy showed randomly arranged non-branching fibers, ranging from 18-24nm in diameter within the mesangium and glomerular basement membranes (see Figure 2). Immuflorescence stain showed a strong smudgy polyclonal IgG and C3 mesangial and capillary loop staining. A Congo red stain was negative for amyloid confirming her diagnosis of crescentic FGN.

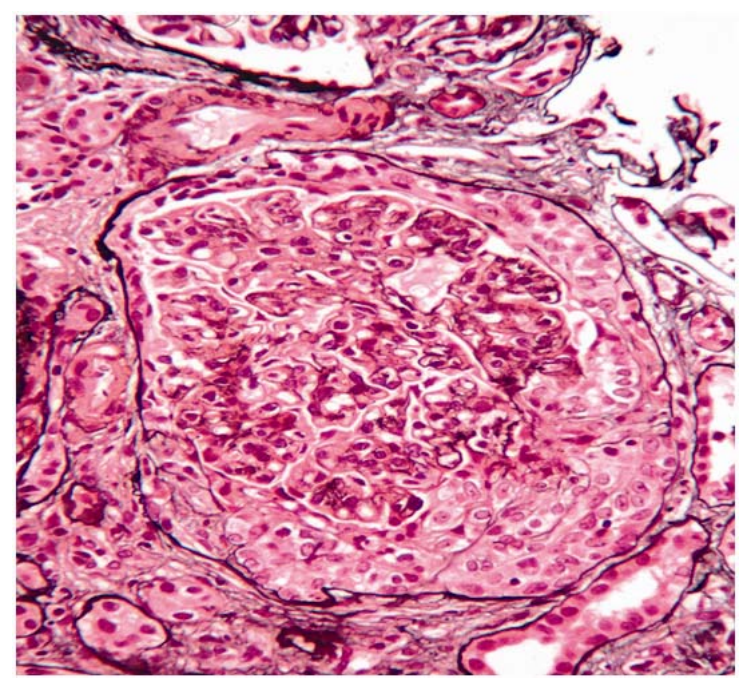

Figure 1. Light microscopy showing endocapillary proliferation and crescent formation

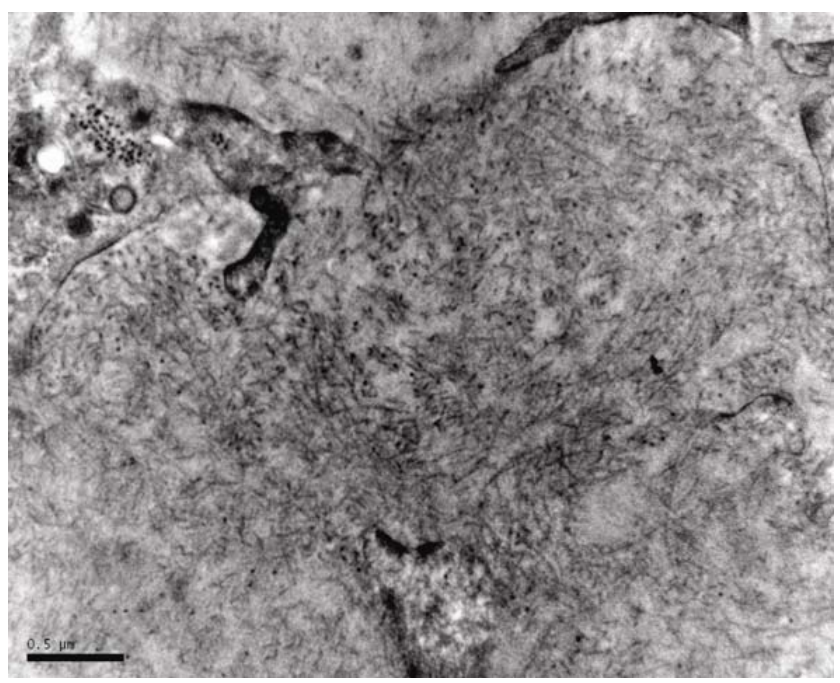

Figure 2. Electron microscopy showing thickened GBM, foot process effacement, Fibrils 18-25 nm in the GBM and mesangium.

We choose euro lupus nephritis protocol with induction treatment using low dose cyclophosphamide 500 mg every 2 week's total of six doses with 3 days of pulse steroids (methylprednisolone 500mg daily) then prednisone $1 \mathrm{mg} / \mathrm{kg}$ (starting at $60 \mathrm{mg}$ daily) tapered over six months down to 5mg/day. Maintenance was with Azathioprine $1.5 \mathrm{mg} / \mathrm{kg}$ at a dose of 75 $\mathrm{mg}$ BID and prednisone at $5 \mathrm{mg}$ daily. 
Table 1. Clinical findings on admission

\begin{tabular}{|c|c|c|c|}
\hline Variables & Normal Range & Result & Unit \\
\hline \multicolumn{4}{|l|}{ Complete blood count } \\
\hline Hemoglobin & $12-16$ & 9.1 & $\mathrm{~g} / \mathrm{dL}$ \\
\hline Hematocrit & $35-47$ & 29.4 & $\%$ \\
\hline White blood cell & $4.5-11$ & 12.6 & $\mathrm{k} / \mathrm{uL}$ \\
\hline Platelet count & $150-440$ & 227 & $\mathrm{k} / \mathrm{uL}$ \\
\hline \multicolumn{4}{|l|}{ Chemistry } \\
\hline Sodium & 135-145 & 126 & $\mathrm{mEq} / \mathrm{L}$ \\
\hline Potassium & $3.5-5.0$ & 5.2 & $\mathrm{mEq} / \mathrm{L}$ \\
\hline Chloride & 99-109 & 92 & $\mathrm{mEq} / \mathrm{L}$ \\
\hline Bicarbonate & $22-33$ & 23 & $\mathrm{mEq} / \mathrm{L}$ \\
\hline Blood urea nitrogen & $6-20$ & 63 & $\mathrm{mg} / \mathrm{dL}$ \\
\hline Creatinine & $0.6-1.10$ & 6.25 & $\mathrm{mg} / \mathrm{dL}$ \\
\hline Glucose & $70-105$ & 98 & $\mathrm{mg} / \mathrm{dL}$ \\
\hline Calcium & 8.5-10.5 & 7.8 & $\mathrm{mg} / \mathrm{dL}$ \\
\hline Total Protein & $6.2-8.3$ & 6.1 & $\mathrm{~g} / \mathrm{dL}$ \\
\hline Albumin & $3.4-4.1$ & 3.5 & $\mathrm{~g} / \mathrm{dL}$ \\
\hline \multicolumn{4}{|l|}{ Complement } \\
\hline C3 & $84-160$ & 98 & $\mathrm{mg} / \mathrm{dL}$ \\
\hline $\mathrm{C} 4$ & $12-36$ & 46 & $\mathrm{mg} / \mathrm{dL}$ \\
\hline \multicolumn{4}{|l|}{ Autoimmune Studies } \\
\hline ANA & & $<40$ & \\
\hline Anti-DNA Antibody & & Negative & \\
\hline Glomerular Membrane Antibody & & $<1.0$ (not detected) & \\
\hline HepB serology & & Negative & \\
\hline Hep A Ab-IgM & & Negative & \\
\hline Hep C Ab & & Negative & \\
\hline \multicolumn{4}{|l|}{ Urinalysis } \\
\hline Protein & & $2+$ & \\
\hline $\mathrm{RBC}$ & & TNTC & \\
\hline Leukocyte Esterase & & $2+$ & Urine eosinophil- Neg \\
\hline WBC & & $20-50$ & \\
\hline Nitrite & & Negative & \\
\hline Urine Culture & & No growth & \\
\hline
\end{tabular}

She responded dramatically to this regimen and was off hemodialysis after 3 weeks. She was discharged from the hospital and her creatinine a year later was $1.6 \mathrm{mg} / \mathrm{dl}$ corresponding to an eGFR of $40 \mathrm{ml} / \mathrm{min}$. Her proteinuria is down to $400 \mathrm{mg}$ /24hr (see table 2). 
Table 2. Selected renal function labs with treatment

\begin{tabular}{llll}
\hline & Prior to treatment & at $\mathbf{6}$ months & at $\mathbf{1}$ year \\
\hline BUN & 48 & 78 & 72 \\
Creatinine $(\mathrm{mg} / \mathrm{dl})$ & 6.25 & 2.13 & 1.60 \\
Proteinuria $(\mathrm{g} / 24 \mathrm{hr})$ & 5.8 & 1.2 & 0.4 \\
\hline
\end{tabular}

\section{Discussion}

There are several case reports of FGN treated with cyclophosphamide. However in these case reports, higher cumulative doses of cyclophosphamide was used compared to the $3 \mathrm{~g}$ total cumulative dose used in the Euro Lupus Nephritis trial protocol. To our knowledge there is no published case report treating FGN with low dose cyclophosphamide therapy.

We adopted the Euro lupus nephritis protocol of low dose cyclophosphamide treatment firstly because the efficacy of this regimen was already well established for proliferative Lupus nephritis management.

Secondly, FGN is thought to be possibly an immune complex mediated disease in part because of the finding of IgG complexes on immunoflorescent stains in the fibrillary deposits. Cyclophosphamide an alkylating agent is known to suppress T-helper cell functions with prolonged reduction of B cells and ultimately suppressing IgG immune complex production. Lastly we chose a low dose cyclophosphamide regimen because our patient was critically ill at presentation and we felt this regimen would offer a lower side effect profile.

Our patient ultimately responded very well to this regimen and was able to get off hemodialysis after 3 weeks of treatment. She did not have any significant treatment related complications except for steroid related hyperglycemia which improved as we weaned her prednisone doses. She has remained in remission with stable stage 3 CKD after 1 year of follow up.

\section{Conclusion}

We have described a case of rapidly progressing renal failure due to cresentic FGN treated with a Low dose cyclophosphamide based regimen. The impressive response to treatment in this case coupled with overall low side effect profile makes this option appealing for treatment of cases with similar presentation.

\section{References}

[1] Samih H. Nasr, Anthony M. Valeri. Fibrillary Glomerulonephritis: A Report of 66 Cases from a Single Institution. Clin J Am Soc Nephrol. 2011; 6: 775-784. http://dx.doi.org/10.2215/CJN.08300910

[2] Iskandar SS, Falk RJ, Jennette JC. Clinical and pathologic features of fibrillary glomerulonephritis. Kidney Int. 1992; 42: 1401-1407. http://dx.doi.org/10.1038/ki.1992.433

[3] Rosenstock JL, Markowitz GS, Valeri AM, Sacchi G, Appel GB, D'Agati VD. Fibrillary and immunotactoid glomerulonephritis: Distinct entities with different clinical and pathologic features. Kidney Int. 2003; 63: 1450-1461. http://dx.doi.org/10.1046/j.1523-1755.2003.00853.x

[4] Fogo A, Qureshi N, Horn RG. Morphological and clinical features of fibrillary glomerulonephritis versus immunotactoid glomerulopathy. Am J Kidney Dis. 1993; 22: 367-377. http://dx.doi.org/10.1016/S0272-6386(12)70138-5

[5] Charles E. Alpers and Jolanta Kowalewska , Fibrillary Glomerulonephritis and Immunotactoid Glomerulopathy. J Am Soc Nephrol. 2008; 19 (1): 34-37. http://dx.doi.org/10.1681/ASN.2007070757

[6] Shalini Nilajgi, John Paul Killen, Richard Baer, Patricia Renaut and Murty Mantha: Fibrillary glomerulonephritis: presenting as crescentic glomerulonephritis causing rapidly progressive renal failure NDT Plus. 2011; 4: 413-415 
[7] Bhat ZY, Zen X, Hingorani J, Khan S, Mohanty MJ. Fibrillary glomerulonephritis in a patient with systemic lupus erythematosus: a rare association. Int Urol Nephrol. 2013 Feb; 45(1): 281-4. http://dx.doi.org/10.1007/s11255-011-0073-0

[8] Guerra G, Narayan G, Rennke HG, Jaber BL. Crescentic fibrillary glomerulonephritis associated with hepatitis C viral infection. Clin Nephrol. 2003; 60: 364-368. http://dx.doi.org/10.5414/CNP60364

[9] Purva S, Michael K. Fibrillary Fibrillary Glomerulonephritis Presenting as Rapidly Progressive glomerulonephritis. Am J Kidney Dis. 2012; 60: 157-159. http://dx.doi.org/10.1053/j.ajkd.2011.12.024

[10] Bridoux F, Hugue V, Coldefy O, Goujon JM, Bauwens M, Sechet A, et al. Fibrillary glomerulonephritis and immunotactoid (microtubular) glomerulopathy are associated with distinct immunologic features.Kidney Int. 2002; 62: 1764-1775. http://dx.doi.org/10.1046/j.1523-1755.2002.00628.x

[11] Vincent Javaugue, Alexandre Karras, Long-term Kidney Disease Outcomes in Fibrillary Glomerulonephritis: A Case Series of 27 patients. Am J Kidney Dis. 2013; 62 (4): 679-690. http://dx.doi.org/10.1053/j.ajkd.2013.03.031

[12] Michael Collins, Sankar D Navaneethan, James Sloand, BradRovin, rituximab: a novel treatment option for fibrillary glomerulonephritis? Am J Kidney Dis. 2008; 52 (6): 1158-1162. http://dx.doi.org/10.1053/j.ajkd.2008.07.011

[13] Fre'de'ric A, Immunosuppressive Therapy in Lupus Nephritis, The Euro-Lupus Nephritis Trial, a Randomized Trial of Low-Dose Versus High-Dose Intravenous Cyclophosphamide. Arthritis \& rheumatism. 2002; 46(8): 2121-2131.

http://dx.doi.org/10.1002/art.10461 